\title{
The Impact of Sales Integration on Innovation Capacity from a Corporate Foresight Perspective (Work-In-Progress)
}

\author{
Simon Dummel \\ University of Salzburg Business School, Sigmund-Haffner-Gasse 18, \\ 5020 Salzburg, Austria, E-mail: simondummel@msn.com
}

\begin{abstract}
This paper is a work-in-progress paper accompanying a dissertation project with the working title 'The Impact of Sales Integration on Innovation Capacity from a Corporate Foresight Perspective'. It provides a literature background, research aims and initial hypotheses collection for upcoming empirical work. The field of research involves Strategic Management, Innovation Management and Corporate Foresight. It is said that salespeople are the ear to the customer and no other function is as close to the market. Hence, salespersons obtain specific market knowledge that can create value for the organization. In this context, Corporate Foresight came to importance in order to create scenarios of future developments that are triggered by dynamic business environments. So, the question arises of how salespersons add to knowledge creation in Innovation and Foresight Management of a firm. Is the sales function well integrated into systematic knowledge exchange or are silos more present? With regard to the problem there is only scarce research work published yet. Especially, in connection with innovation capacity the value contribution of sales involvement requires more detail investigation. So, the author aims at detecting patterns of sales integration into intelligence processes within the foresight framework. Causal effects shall be observed illustrating how sales knowledge is diffused and used internally. Research hypotheses were derived from literature review and existing theories. A study in the manner of a crosssectional survey will be chosen as research design. A written online survey shall be conducted.
\end{abstract}

Keywords: Corporate Foresight; Innovation Capability, Sales Integration 


\section{$2^{\text {nd }}$ International Conference on Future of}

\section{Introduction}

In today's dynamic business environments consumer demands increase and technologies become more complex ${ }^{1}$. In such an environment forecasts of future developments and potentials can prepare firms for change. In corporate context this discipline is portrayed as Corporate Foresight: organizations use special methods to detect, anticipate and respond to future needs ${ }^{2}$. Overall, holistic foresight systems are still lacking widely.

For lack of time, companies frequently pursue the strategy of prematurely offering products that are not sufficiently developed on the market. So, customers and employees with customer contact are still among the most important sources when it comes to knowledge transfer from the markets. Managing networks and cooperation become critical success factors. As a source of customer-specific information sales units can supplement technical knowledge in new product development and increase its success ${ }^{3}$. On the other hand, sales units are mostly managed based on forecasts, so to say rigid and inflexible.

This leads to the question of whether organizations with an importance of sales activities have other mechanisms for the design of foresight and innovation systems. Can ideas from salespersons in an ambiguous environment with the claim to a certain agility be decisively placed or does innovation belong to other functions? These conflicting assumptions emphasize the interest that sales units have in providing market intelligence.

This research paper provides a description of the intended doctoral thesis with the working title 'The Impact of Sales Integration on Innovation Capacity from a Corporate Foresight Perspective'.

\section{Preliminary Literature Analysis and Contribution to Theory}

This chapter shall illustrate gaps in current data and the dissertation's value contribution to the bodies of knowledge. The thesis aims to be a preliminary study for the research of Corporate Foresight in organizations. The literary basis of the work includes research in the fields of Corporate Foresight, Strategic Management, Innovation Management and Knowledge Management. In general, it can be stated that there is a lack of conceptual and empirical explanations on Corporate Foresight ${ }^{4}$. In particular, in connection with the sales function a significant research gap has been identified.

Corporate Foresight aims at preparing for strategic decision-making in order to ensure future competitiveness and to support innovation capacity of firms. In this context, it can represent an early warning system. Second, Corporate Foresight can support decision-making in a

\footnotetext{
${ }^{1}$ Rohrbeck \& Gemünden, 2011, p. 232

${ }^{2}$ Rohrbeck, 2011, p. 1

${ }^{3}$ Ernst, Hoyer \& Rübsaamen, 2010

${ }^{4}$ Popper, 2008, p. 64
} 


\section{$2^{\text {nd }}$ International Conference on Future of}

\section{BUSINESS, MANAGEMENT \& ECONOMICS}

strategic and forward-thinking way. Third, it can directly have impact on decisions in the context of priority setting in research and development activities. Fourth, Corporate Foresight can provide insights to strategy definition. Another function is the enhancement of innovation capabilities $^{5}$.

A Corporate Foresight Maturity Model as a theoretical framework for the assessment of Corporate Foresight activities was developed ${ }^{6}$. Within this, Corporate Foresight is considered an (organizational) dynamic capability being able to impact the quality of outcomes. So, every organization has unique and differentiated foresight capabilities. There are five categories that determine Corporate Foresight capabilities. The higher the maturity, the more value can be expected from Corporate Foresight. Therefore, it can be assessed

- how and where information is used within the firm,

- which foresight methods are applied,

- which people are integrated,

- at which organizational level activities are initiated and

- whether the corporate culture promotes forward-thinking.

There are three crucial roles Corporate Foresight can take in Innovation Management: Corporate Foresight functions as input provider, strategic instrument or continuous service ${ }^{7}$. Conducting Corporate Foresight activities has a positive effect of the corresponding role. Hence, good foresight work results in improved opportunity identification and risk assessment along the entire innovation process.

From the Innovation Management point of view there are few research papers available that investigate the effect of salespersons in innovation. Accordingly, sales units' intelligence impacts new product performance positively ${ }^{8}$. Extended by a more strategy-oriented definition of innovation capacity and a focus on Corporate Foresight activities, there are no research papers that investigate sales roles within.

The intended research shall focus on profit-oriented organizations (business context) that follow foresight patterns (forward-thinking) and have specialized sales structures (sales forces, aftersales), especially in business-to-business markets.

Empirical explanations on Corporate Foresight will contribute to theory and add data on the integration possibilities of sales in foresight settings. Furthermore, the thesis aims to confirm previous research on Corporate Foresight. Besides, it initially investigates the interrelation of the variables

- Sales Integration and Corporate Foresight Maturity

\footnotetext{
${ }^{5}$ Becker, 2002

${ }^{6}$ Rohrebck, 2011

${ }^{7}$ Rohrbeck \& Gemünden, 2011

${ }^{8}$ Joshi, 2010; Kuester \& Rauch, 2016
} 


\section{$2^{\text {nd }}$ International Conference on Future of}

- Sales Integration and Sales Performance

- Sales Integration and Strategic Innovation Orientation

- Sales Integration and Innovation Capacity.

It contributes to the body of innovation literature by investigating the impact of Corporate Foresight on innovation performance and the integration of sales in Innovation Management.

For the research object of sales units, it determines the value of Corporate Foresight and puts the focus on a broader sales integration, not only in new product developments but in overarching innovation strategy orientation pursued by all sales functions, not only sales forces.

The practical value will lie in a better managerial cognition of Corporate Foresight and a contribution to sales transformation processes, respectively the roles of sales staff in foresight. There will be new insights by developing a new concept for sales integration in foresight and applying a methodologically new approach with an up-to-date research framework including new variables. International comparability is targeted, too.

\section{Research Aim and Questions}

The major research aim is to make a theoretical and practical contribution to whether companies integrate sales units' knowledge in order to identify (future) developments. The aim is to evaluate how knowledge is externally generated, internally stored, distributed and processed. Corporate Foresight shall be given new perspectives by investigating the effect of sales integration on Corporate Foresight and innovation capacity. Is generated knowledge explicitly considered in product innovations or is the use of information generated by sales units limited to internal process innovations?

Second, the goal is to characterize the types of cooperation between sales units and their environment. How far are the systems developed, what are the motivations for an implementation and what strategic role do they play within the innovation process? Are certain foresight methods used and to what extent is knowledge transferred to the company? Who are the protagonists and which are particularly intensive (strategic) partnerships? Can they be represented in a universally valid network?

Finally, it should be examined which mechanisms optimally integrate sales units into the foresight process. The intention is to develop a general model of the role of sales in Corporate Foresight, propose implications for the design of that role and provide Innovation Management with further empirical evidence. So, this research aims to contribute to a richer understanding of Corporate Foresight, especially in innovation context, and promotes further discussions. 


\section{$2^{\text {nd }}$ International Conference on Future of BUSINESS, MANAGEMENT \& ECONOMICS}

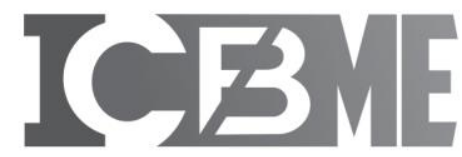

4-6 September, 2020 PRAGUE, CZECH

To summarize the research questions, this work aims to

- give an overview of Corporate Foresight activities conducted by salespersons,

- describe motivations and influencing factors in the context of their practices,

- investigate their effect on overall foresight and innovation capacity,

- propose implications for the strategic use of sales units in the foresight process

- And identify significant trends.

\section{Research Method}

In order to validate the central constructs and formulations of the research model, a qualitative expert survey on the topics of strategy, innovation and knowledge transfer in sales units shall be conducted. Selected project managers, sales managers, executives and other decisionmakers shall be interviewed for the confirmation of introduced hypotheses and give an initial assessment of the practice and feasibility of sales innovations, especially in foresight context.

The second research design is an ex-post facto study in form of a cross-sectional survey. The method shall be a written, standardized online survey amongst sales units, (innovation and strategy) project staff and R\&D employees of firms. The results shall be presented descriptively and the research questions (hypotheses) answered by conducting structural equation modeling. Additionally, a (social) network analysis shall be conducted to highlight the protagonists in the network setup and identify functions that act as major hubs.

\section{Research Model Development and Initial Hypotheses Collection}

Based on the literature gaps identified above the author created an initial research model including the constructs of Sales Integration into the market intelligence process, Corporate Foresight Maturity of the firm, individual Salesperson's Performance and the firm's overall Innovation Capability. Figure 1 explains the constructs and their relationships. The relevant hypotheses are as follows:

H1: There is a significant positive effect of Sales Integration on Corporate Foresight Maturity.

$\mathrm{H} 2$ : There is a significant positive effect of Sales Integration on Innovation Capacity.

H3: Corporate Foresight Maturity has a positive mediating effect on the relationship between Sales Integration and Innovation Capacity.

H4: There is a significant positive effect of Sales Integration on Sales Performance. This relationship is moderated by Environmental Dynaxity (H4a).

H5: Environmental Dynaxity has a positive moderating effect on the relationship between Sales Integration and Innovation Capacity. 


\section{$2^{\text {nd }}$ International Conference on Future of \\ BUSINESS, MANAGEMENT \& ECONOMICS}

Figure 1: Research Model

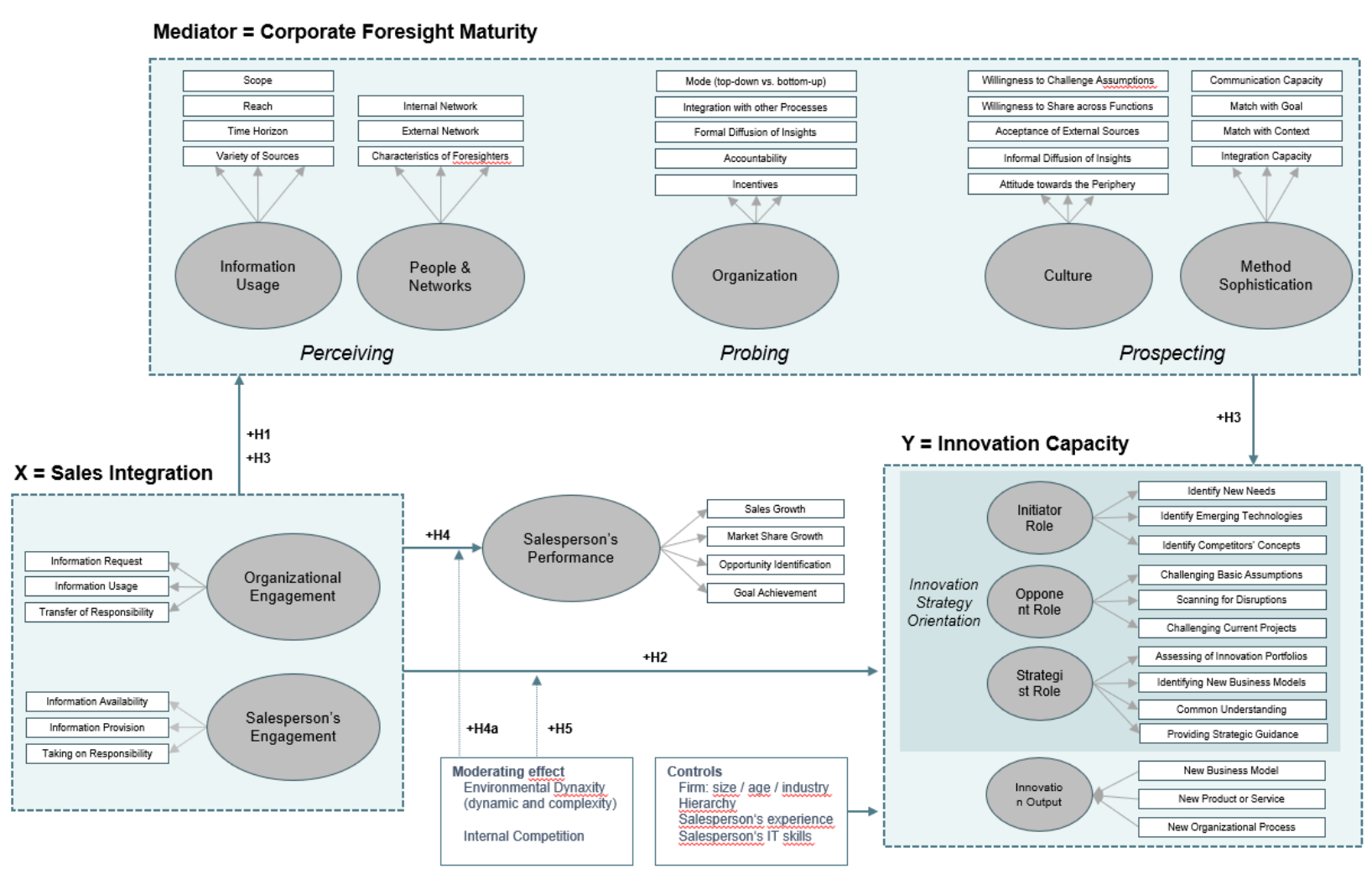

Source: own figure developed for research.

Sales Integration can be defined through Organizational Engagement and the Salesperson's Engagement ${ }^{9}$. This construct has to be defined more precisely, whereas a factorial analysis has to be conducted.

Foresight Maturity can be defined as the overall level of information usage, people and network size (perceiving), organization (probing), culture and method sophistication (prospecting $)^{10}$. This construct has been validated through several studies on foresight maturity in firms ${ }^{11}$.

Innovation Capacity is a broadly defined construct. First, the author aims to investigate the Innovation Strategy Orientation using the three roles of Corporate Foresight in Innovation Management ${ }^{12}$. Second, the actual Innovation Output shall be measured according to the innovativeness of a concrete product/service/process and areas of its application.

\footnotetext{
${ }^{9}$ Homburg, Sieberz \& Prigge, 2014

${ }^{10}$ Højland \& Rohrbeck, 2018

${ }^{11}$ Højland \& Rohrbeck, 2018; Rohrbeck \& Kum, 2018

${ }^{12}$ Rohrbeck \& Gemünden, 2011
} 


\section{$2^{\text {nd }}$ International Conference on Future of}

Salesperson Performance can theoretically be measured in various ways. The author wants to capture growth in sales figures and market share, opportunity identification and goal achievement.

\section{Conclusion}

This paper describes the project of empirically investigating the effects of sales integration in market intelligence activities and the impact on a firm's innovation capacity from a Corporate Foresight point of view. It highlights the importance of understanding the crucial role individual salespersons have in sharing market knowledge. The author identified literature gaps regarding salespersons and their involvement in innovation and foresight processes. A research model was developed and hypotheses were derived from literature reviews and theories. In the next step the theoretical constructs introduced have to be validated and the framework adjusted before a questionnaire can be set up for empirical study.

\section{References}

[1]Becker, P. (2002). Corporate foresight in Europe. A First Overview, RTK2 Scientific and Technological Foresight, European Commission.

[2]Ernst, H., Hoyer, W.D. \& Rübsaamen, C. (2010). Sales, Marketing, and Research-andDevelopment Cooperation across New Product Development Stages: Implications for Success, Journal of Marketing, 74(5), 80-92.

[3]Højland, J. \& Rohrbeck, R. (2018). The role of corporate foresight in exploring new markets - evidence from 3 case studies in the BOP markets, Technology Analysis \& Strategic Management, 30(6), 734-746.

[4]Homburg, C., Sieberz, I.; Prigge, J.K. (2014). Einbindung des Vertriebs in die Produktentwicklung. IMU Research Insights Mannheim 022 [working paper]

[5] Joshi, A.W. (2010). Salesperson Influence on Product Development: Insights from a Study of Small Manufacturing Organizations, Journal of Marketing, 74(1), 94-107.

[6] Kuester, S. \& Rauch, A. (2016). A job demands-resources perspective on salespersons' market intelligence activities in new product development, Journal of Personal Selling \& Sales Management, 36(1), 19-39.

[7] Popper, R. (2008). How are Foresight Methods Selected? Foresight, 10(6), 62-89.

[8]Rohrbeck, R. (2011). Corporate Foresight. Towards a Maturity Model for the Future Orientation of a Firm. Physica.

[9]Rohrbeck, R., \& Gemünden, H. G. (2011). Corporate Foresight: Its Three Roles in Enhancing the Innovation Capacity of a Firm, Technological Forecasting \& Social Change, 78(2), 231-243.

[10] Rohrbeck, R. \& Kum, M.E. (2018). Corporate foresight and its impact on firm performance: A longitudinal analysis, Technological Forecasting and Social Change, 129, 105-116. 